\title{
Alfuzosin Hydrochloride
}

National Cancer Institute

\section{Source}

National Cancer Institute. Alfuzosin Hydrochloride. NCI Thesaurus. Code C53408.

The hydrochloride salt of alfuzosin, a quinazoline compound with smooth musclerelaxing activity. Alfuzosin selectively binds to and antagonizes post-synaptic alpha-1adrenoreceptors in smooth muscle of the prostate, bladder base, bladder neck, prostatic capsule, and prostatic urethra, initiating relaxation of smooth muscle and resulting in improvement of urine flow and the symptoms of benign prostatic hyperplasia (BPH). This agent also blocks alpha-1-adrenoreceptors in peripheral vascular smooth muscle, resulting in vasodilatation and a decrease in peripheral vascular resistance. 